DIW BERLIN

Discussion Papers

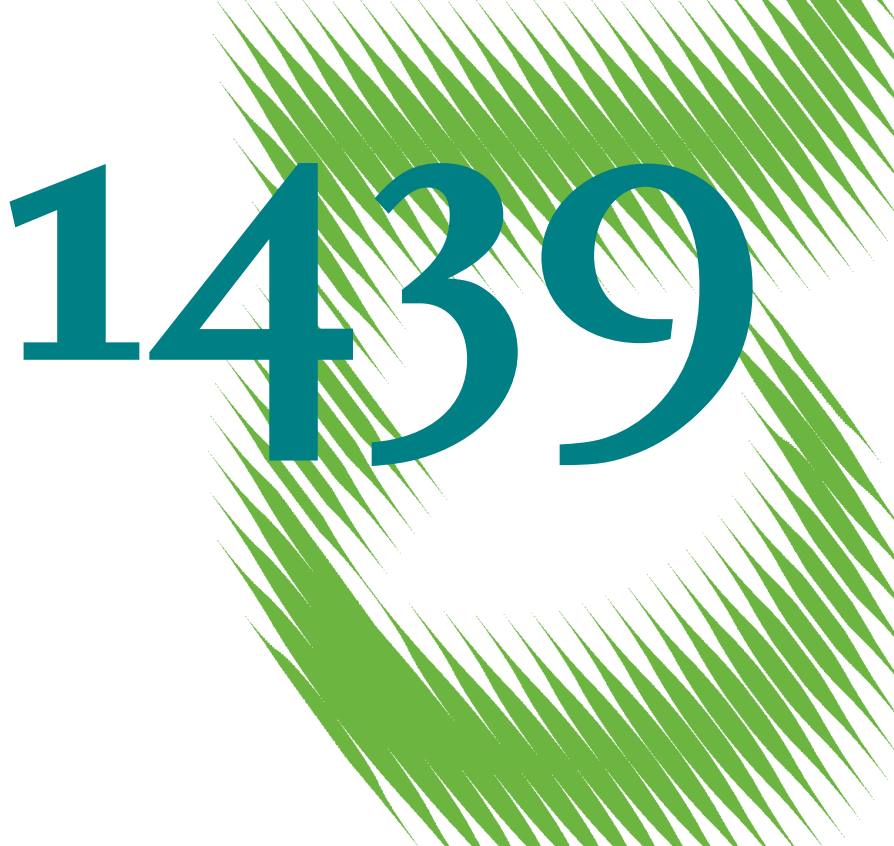

Would I Care if I Knew?

Image Concerns and

Social Confirmation in Giving 
Opinions expressed in this paper are those of the author(s) and do not necessarily reflect views of the institute.

IMPRESSUM

(C) DIW Berlin, 2014

DIW Berlin

German Institute for Economic Research

Mohrenstr. 58

10117 Berlin

Tel. +49 (30) $89789-0$

Fax +49 (30) $89789-200$

http://www.diw.de

ISSN electronic edition 1619-4535

Papers can be downloaded free of charge from the DIW Berlin website:

http://www.diw.de/discussionpapers

Discussion Papers of DIW Berlin are indexed in RePEc and SSRN:

http://ideas.repec.org/s/diw/diwwpp.html

http://www.ssrn.com/link/DIW-Berlin-German-Inst-Econ-Res.html 


\title{
Would I Care if I Knew? \\ Image Concerns and Social Confirmation in Giving
}

\author{
Alexander S. Kritikos ${ }^{1}$ \\ Jonathan H. W. Tan ${ }^{2}$ \\ DIW Berlin \\ University of Nottingham
}

December 2014

\begin{abstract}
This paper experimentally investigates the nature of image concerns in gift giving. For this, we test variants of dictator and impunity games where the influences of social preferences on behavior are kept constant across all games. Givers maximize material payoffs by pretending to be fair when receivers do not know the actual surplus size, implying that portraying an outward appearance of norm compliance matters more than actual compliance. In impunity games, receivers can reject gifts with no payoff consequence to givers. In the face of receivers' feedback, some givers ensure positive feedback by donating more while some avoid negative feedback by not giving at all. Removing feedback reduces the incentive to give altogether. Differing behavior in the four games implies that social confirmation plays a crucial role in the transmission of image concerns in giving.
\end{abstract}

JEL classification: C78; C92

Keywords: Dictator; impunity; experiment; image; social confirmation

\footnotetext{
*We thank Friedel Bolle, Yves Breitmoser, Werner Güth, Manfred Holler, Wolfgang Leininger, Axel Ockenfels for their helpful comments. The financial support of the German Research Foundation (BO 747/8-1) is gratefully acknowledged.

${ }^{1}$ Alexander S. Kritikos is Research Director at the German Institute for Economic Research (DIW Berlin), Professor in Economics at the University of Potsdam and Research Fellow of the IZA, Bonn, and of the IAB, Nuremberg, e-mail: akritikos@diw.de.

${ }^{2}$ Jonathan H.W. Tan (corresponding author) is Associate Professor in Economics at the University of Notthingham, e-mail: Jonathan.Tan@nottingham.ac.uk.
} 



\section{Introduction}

People have image concerns when they care about how they appear to others- those who judge them based on the choices they make. These people are also averse to deviating from expectations of how one ought to behave and are willing to trade off monetary payoffs with image utility. Research shows the influence of image concerns on prosocial behavior, in particular for gift giving (e.g., Andreoni and Bernheim, 2009; Ariely et al., 2009; Dana et al., 2006, 2007; Franzen and Pointner, 2012). Dana et al. (2006) argue that 'giving often reflects a desire not to violate others' expectations rather than a concern for others' welfare per se" (p. 193). Expectations might be anchored on reference points such as norms of fairness (Andreoni and Bernheim, 2009; Krupka and Weber, 2013). Our interest goes beyond giving due to social preferences, such as altruism (Eckel and Grossman, 1996; Andreoni and Miller, 2002; Breitmoser and Tan, 2013), fairness (Fehr and Schmidt, 1999; Bolton and Ockenfels, 2000), or efficiency concerns (Kritikos and Bolle, 2001; Charness and Rabin, 2002; Engelmann and Strobel, 2004). In this paper, we aim to understand how people value their image and how image concerns transmit to behavior.

We jointly analyze four games across which theories of altruism, efficiency, fairness, or reciprocity concerns predict the same behavior. First, we have a standard dictator game with complete information (DG-CI) serving as benchmark. Second, we use a dictator game with incomplete information (DG-II) where Nature chooses between a large and small surplus, and only the giver knows the true surplus size. Ockenfels and Werner (2012) independently tested this game in a newspaper experiment. It allows us to test if giving is motivated by the desire to meet the receiver's expectation per se, rather than what one truly ought to give based on common expectations under complete information. ${ }^{3}$

The third and fourth games extend the impunity game first presented by Bolton and Zwick (1995), where a receiver can reject gifts but rejection bears no pecuniary consequence to the giver - the giver acts under impunity. In the impunity game with complete information (IG-CI), givers are provided feedback on receiver decisions, i.e. the receiver provides social confirmation by responding to inform the giver on whether

\footnotetext{
${ }^{3}$ A classic example of giving under incomplete information is found in Luke 5 of the Bible. Ananias and Sapphira lied to the Apostles by under declaring the value of the land they had just sold. This was because they were expected to contribute all their proceeds to the Church, and by lying they might secretly withhold some money for themselves. They assumed that the Apostles did not know the true value of their land.
} 
expectations were met. In our impunity game with incomplete information (IG-II), givers do not get feedback on the receiver's decisions, i.e. the giver does not obtain social confirmation on the receiver's perception. In this sense we are able to test the effect of allowing receivers to response and the value of feedback on such responses.

Thus, our experiment tests the robustness of giving to modifying the action space and information structure in a dictator game in ways that previous social preference theories are insensitive to, but are picked up by image concerns and are of external validity in terms of real world applications. For instance, people typically receive offers without knowing the available surplus. Gifts can either be accepted graciously or rejected disdainfully when insolent pittances have been offered. Would givers behave differently if they would eventually find out what the receiver actually thinks? Relatedly, DellaVigna et al. (2012) find that otherwise unwilling donors give when subject to social pressure, suggesting the importance of understanding the power of feedback on perceptions. ${ }^{4}$ Such insights can guide the design of fundraisers or other public good settings.

We observe that the distributions of gifts vary significantly across the four games. The DG-CI has results comparable to previous experiments. In the DG-II, we observe a large cluster of reduced offers mimicking fair splits of the small surplus when the surplus of the giver was large. In the IG-CI, we find more extreme offers: more subjects give nothing or half the surplus than in the baseline, while receivers reject majority of gratuitous offers. Finally, we find that in the IG-II, gratuitous offers close to zero vanish, and the majority of subjects gave nothing while there is still a certain share of givers transferring a positive amount of money. The observed variety of behavior confirms that image concerns are self-serving and that it values social confirmation, while social preference theories do no predict that gift giving is sensitive to the information structure of the context.

Section 2 describes experiments related to our work. Section 3 presents the experimental games, and states behavioral hypotheses. Section 4 explains the experimental logistics. Section 5 reports the results. Section 6 discusses and concludes.

\footnotetext{
${ }^{4}$ Similar observation is reported by Ariely et al. (2009) and Andreoni and Rao (2011), who explain the changing behavior by "the power of asking."
} 


\section{Related literature}

We use the dictator game (Forsythe et al. 1994) as a benchmark against which the other games can be compared. Previous experiments show three stylized facts, as reviewed by Engel (2011). First, the average transfer to receivers is in most games somewhere between 20 and 30 per cent. Second, the distribution of transfers is skewed to the left with transfers of more than 50 per cent being rarely observed. Third, the zero transfer is also commonly chosen; it is the rational transfer of an egoist.

Our second game, the dictator game with surplus size unknown to the receiver is inspired by Güth et al. (1996). They employ a two-level ultimatum game with three players who take turns making an offer, while the third player can either accept or reject a surplus of a size known only to the first two players. ${ }^{5}$ The main insight of Güth et al.'s ultimatum game under incomplete information is that, given the veto power of receivers, virtually all givers who received a large pie hide behind the small pie and transfer an amount equal to the half of the small pie to the receiver. The main difference between our game and the ultimatum game under incomplete information is that receivers in our game are unable to make decisions of payoff consequence for the giver, and this removes confounding effects due to the giver's fear of rejection.

Andreoni and Bernheim (2009) model image concerns by describing how givers suffer disutility when they are believed to have deviated from a social norm, which they assume to be the equal $50-50$ split. ${ }^{6}$ They modify the dictator game by introducing a probabilistic exogenous intervention by Nature that overrides the giver (who must split $\$ 20)$ to determine the receiver's payoff. If Nature intervenes, the receiver gets $\$ 0$ in one treatment and $\$ 1$ in another. Receivers do not know if their payoff is attributable of the giver or Nature. They find that as the probability of intervention increases, the frequencies of givers allocating $\$ 0$ and $\$ 1$ in the respective treatments increases, while the frequency of those offering the equal split decreases in both treatments. Nature probabilistically determines the surplus rather than the receiver's payoff in our experiment, so we can test the salience and attraction of the "equal split" as a reference point.

\footnotetext{
${ }_{6}^{5}$ See also Straub and Murnighan (1995) or Croson (1996).

${ }^{6}$ Andreoni and Bernheim (2009) also review the external validity of this rule as applied in institutions and to inheritance.
} 
Our approach relates to recent models of image concerns with an underlying belief function regarding one's type, being dependent on gifts anchored to a fairness norm (see Andreoni and Bernheim, 2009, or Dana et al., 2006). In the "plausible deniability" treatment of Dana et al. (2007), the chance that nature would intervene and make a random choice on a giver's behalf increases with a giver's delay in deciding. Givers could thus also avoid feeling that they have behaved unfairly within the moral wiggle room that nature's possible intervention afforded them. In ours, though, givers can trade off the appearance of true fairness to others, and thus, also to themselves, in return for a false appearance of fairness to others and increased pecuniary profit to themselves. The DG-II provides givers with the option to deceive receivers with seemingly fair offers.

In reciprocity models, players consider others intentions. Charness and Rabin (2002) and Dufwenberg and Kirchsteiger (2004) model intentions based on social welfare comparisons across choices. Dynamic reciprocity models compute equilibrium responses based on beliefs of each other's plans and actions. Falk and Fischbacher (2006) combine intentions with inequity aversion, and predict that people behave based on the belief of what the other would do in his shoes. As discussed by Dana et al. (2006), image concerns are compatible with Battigalli and Dufwenberg's (2009) dynamic psychological games, where utility contains an image component measuring the deviation of gifts from, for example, the equal split as a reference point or expectation benchmarked on a fairness norm. Bicchieri and Chavez (2010) test an ultimatum game with asymmetric information on offer choices. They find that behavior and perceptions depend on beliefs of how one ought to behave, guided by a fairness norm.

We further build on the understanding of image concerns with the help of impunity games, inspired by Bolton and Zwick (1995). In their game, receivers can reject the giver's gift, but in contrast to the ultimatum game the rejection does not affect the givers' payoff. Bolton et al., (1998) and Greiner (2004) test only binary choices between predefined allocations. Many givers offered only the small share of the surplus rather than the equal split. In their experiment, rejections are not observable by receivers.

Our experiment differs in two ways. We provide givers with feedback on receiver responses in the IG-CI. Second, we use a smoother action space. This allows direct comparison of distributions across games, and direct tests of whether subjects 
value social confirmation. Rejections constitute negative feedback, implying negative image and disutility for image concerned givers. Allowing receivers to accept or reject offers augments the dictator game with incentives for the giver to pursue positive feedback or by raising higher offers to increase chances of acceptance. Alternatively, one may offer nothing anticipating that low offers entail monetary cost but are likely to result in rejection and image loss. Removing feedback in the IG-II removes social confirmation incentives.

\section{Games}

This section presents the games and analyzes them under the assumptions of selfinterest, social preferences, or image concerns. All games have two players, namely a giver and a receiver. The giver must divide a surplus. We test two dictator games (DG) where the receiver can only accept what was offered by the giver. The first is the dictator game with complete information where both players know the surplus size (DG-CI). This game provides a benchmark for comparing our three other games. The second dictator game has incomplete information (DG-II), with a surplus size observable only by the giver while the receiver is merely informed that the surplus size is large with a certain probability $\alpha$, and small with complementary probability.

The next two games are impunity games (IG), where the receiver can respond to the giver by choosing to either accept or reject the offer. If the offer is rejected, the receiver gets nothing, but this will not affect the giver's payoff as he acts under impunity. In the IG with complete information (IG-CI), he is informed of whether his offer was accepted or rejected by the receiver. In the IG with incomplete information (IG-II) the giver is not informed of the receiver's decision. In all games, both sides knew from the beginning about the own information status and the information status of the other player.

Individuals who are purely money maximizing prefer more money to less. For our analysis, we assume that preferences are symmetric across roles. In our games, if the giver cares only for his material payoff, then he is better off by keeping all the money and offering nothing to the receiver. The same applies to receivers who should accept any offer in the IGs. The assumption of self-interest implies that the receiver does not play any strategic role, because her action does not affect the giver's payoff. 
Moreover, feedback in the IG is extraneous information. Offers in the IG should therefore also be 0 .

H1 (money maximization): If subjects are purely money maximizing, givers will offer 0 in all four games, and receivers will accept all positive offers in the IGs.

Let us now consider individuals with social preferences. Let $x$ denote one's payoff and $y$ denote the co-player's payoff. An altruist has utility described by $U_{\text {alt }}=x+\alpha_{\text {alt }} y$, with $\alpha_{\text {alt }}$ being the strength of altruism. Fehr and Schmidt (1999) and Bolton and Ockenfels (2000) propose that individuals are inequity averse or fair. Bolton and Ockenfels, for instance, describe fairness with $U_{\text {fair }}=x+\alpha_{\text {fair }}\left(\sigma-\frac{1}{2}\right)^{2}$, which is maximized by minimizing the difference between relative payoffs $\sigma=$ $x /(x+y)$, where $\alpha_{\text {fair }}$ captures the normalized strength of fairness concerns. Fehr and Schmidt (1999) describe fairness with $U_{F S}=x-\rho|x-y|-\sigma|y-x|$. Charness and Rabin's (2002) model with efficiency and reciprocity is specified as $U_{\text {rec }}=$ $(1-\rho r-\sigma s-\theta t) x+(\rho r+\sigma s+\theta t) y$ with $r=1$ if $x>y$ and $r=0$ otherwise, $s=1$ if $x<y$ and $s=0$ otherwise, and $t=-1$ if the co-player "misbehaves" by choosing an action that reduces social welfare and $t=0$ otherwise. Efficiency concerns can also be described by the sum of payoffs to all players, namely $U_{\text {eff }}=x+$ $\alpha_{e f f}(x+y)$ (Engelmann and Strobel, 2004).

In the DG-CI and the DG-II with large surplus, altruistic givers offer 0 if $\alpha_{\text {alt }}<1$, are indifferent between offering 0 and everything if $\alpha_{\text {alt }}=1$, and the entire surplus if $\alpha_{\text {alt }}>1$. Fairness predicts positive giving but not more than $1 / 2$ the surplus in DG-CI (for the analysis, see Bolton and Ockenfels, 2000). Efficiency concerns do not influence payoffs in the DGs because social welfare is constant across all strategies. Receivers play no strategic role in DGs, which has two implications. First, offers cannot be rejected in DGs so $j$ cannot behave in the sense of the abovementioned reciprocity model. Offers should then coincide with the prediction of Fehr and Schmidt's (1999) inequity aversion model given the same parameter values. ${ }^{7}$ Second, whether or not the receiver knows the actual surplus size is irrelevant to the giver, because all utilities discussed above are functions of $x$ and $y$, which implies the true

\footnotetext{
${ }^{7}$ The two specifications are equivalent by rearrangement when the reciprocity term is switched off.
} 
value of the surplus that givers know for certain. Offers are therefore the same in DGCI and DG-II for the above preferences.

In IGs, both altruistic receivers (with $\alpha_{\text {alt }}>0$ ) and spiteful receivers (with $\alpha_{\text {alt }}<0$ ) will accept any positive offer because it yields higher income than rejection; even with spite, rejection in IGs does not influence the co-player's income (the receiver's action does not influence the giver's payoff). With fairness concerns, rejection leaves the giver's payoff unchanged but reduces the receiver's payoff and so increases inequity and results in maximum disutility. Thus, fair receivers will also accept any positive offer. ${ }^{8}$ With efficiency concerns, rejections are inefficient and utility reducing proportionate to the amount offered to but rejected by the receiver, implying also that all positive offers will be accepted. Reciprocity does not play a role in this context as the giver can never "misbehave" since there is no way of choosing a socially inefficient allocation, implying the same prediction as inequity aversion.

By backward induction, altruistic or fair givers anticipate that they can always be sure that receivers will keep what they are offered. Thus, the available rejection option will not influence offers in IGs relative to those in DGs. This result holds also with efficiency concerns, when acceptance of the receiver is anticipated. With reciprocity, $j$ is not anticipated to "misbehave", so $i$ remains uninfluenced. Therefore, social preferences predict constant levels of giving across all four games.

H2 (social preferences): If subjects have social preferences, givers will consistently offer the same amount across all four games. As receivers will accept all positive offers in IGs, the sample distribution of offers is constant across games.

Dana et al. (2006) suggest that givers are sensitive to the expectations of receivers, and discuss image concerns of the form $U_{i m g}=x-\alpha_{i m g}|\mu-y|$, following Battigalli and Dufwenberg (2009). The second component is the giver's disutility from the absolute difference between what the receiver expects to receive $\mu$ and her payoff $y$, weighted by a sensitivity parameter $\alpha_{i m g}$. They argue that when $\alpha_{i m g}>1$, givers will conform their behavior to the receivers' expectations. We shall adapt this model to analyze our games with a focus on the basic intuition. We begin by defining $y^{*}$ as the

\footnotetext{
${ }^{8}$ This stands in contrast to ultimatum bargaining, where rejections reduce also the co-players income to the extent that payoffs are equalized at 0 and fairness is achieved, thus inducing higher offers relative to those in DGs.
} 
offer in the DG-CI, where one is indifferent between marginal utilities from additional monetary payoffs or image utility. Turning to the DG-II, because the expected surplus is a weighted sum of the large and small surpluses, it is less than the large surplus so receivers expect less. Keeping $\alpha_{i m g}$ constant across DGs, offers are less in DG-II than in DG-CI (i.e. $\left.y<y^{*}\right)$.

In the IG, if the giver either keeps more or keeps less than expected, then the receiver suffers disutility. ${ }^{9}$ The receiver prefers to reject if this disutility outweighs her material payoff. Because the receiver's payoff will be lower in the case of the giver keeping more versus less than expected, rejection becomes increasingly likely as the receiver is put in an increasingly disadvantageous position relative to being put in an increasingly advantageous position. Backward inducing, the giver considers the tradeoff between monetary payoffs and disutility due to the risk of rejection. This risk implies that from the giver's perspective, the expected payoff of the receiver $E(y)$ is lower in the IGs than in the DG-CI, as it is now a weighted sum of the accepted and rejected offers.

Anticipating this, a giver will raise offers to increase the probability of acceptance if by doing so the decrease in monetary payoff $x$ is outweighed by the increase in expected disutility from image loss $\alpha_{i m g}|\mu-E(y)|$, reduce it if the opposite holds, and maintain it if indifferent. The prediction is therefore to increase or decrease offers from $y^{*}$ to $\bar{y}$ or $\underline{y}$ respectively, depending on how sensitive the giver is to image loss and how probabilities of acceptance increase with offers. Thus, the sample distribution of $y$ varies across games.

H3 (image concerns): If subjects have image concerns, givers will offer $y=y^{*}$ in DG-CI, $y<y^{*}$ in DG-II, $y=\bar{y}$ or $\underline{y}$, with $\underline{y}<y^{*}<\bar{y}$ in IGs, with $0 \leq y^{*} \leq S / 2$, and receivers will reject low offers in IGs. The sample distribution of $y$ varies across games.

\footnotetext{
${ }^{9}$ If the giver would keep less than expected, then the receiver could also suffer disutility. However, the receiver would turn down a more generous offer only if the disutility of suffering from the increased gap between the giver's payoff and his expected payoff outweighs the receiver's increased monetary payoff. In other words: the disutility of suffering needs to increase exponentially if it should over-compensate the utility from an increased monetary payoff.
} 
Finally, whereas there is a risk of image loss in the IG-CI, image loss is uncertain in the IG-II due to the lack of feedback. If image concerns are derived from social confirmation, then uncertainty in the IG-II diminishes the incentive to raise offers to increase the chances of acceptance so as to secure a positive image. This can be modeled by a decrease in the value of the sensitivity parameter $\alpha_{i m g}$. Because the expected image gains from increasing offers toward the equal split become less attractive relative to the IG-CI, the distribution of offers in the IG-II should be biased toward $0 .{ }^{10}$

H4 (social confirmation): If subjects have image concerns in the sense that they value social confirmation, givers will offer $y=0$ in the IG-II.

\section{The Experiment}

The experiment was conducted at a German university with subjects drawn from a pool of economics undergraduate students. They were recruited via email and announcements made during lectures. We ensured that each subject participated only once. Subjects were randomly allocated to one of two rooms upon arrival: one for givers and the other for receivers in the dictator and impunity games. We conducted four large sessions, one for each treatment. We had a total of 440 participants, 120 subjects in DG-CI, 120 in DG-II, 100 in IG-CI, and 100 in IG-II. In the two DG games there were 60 dictators and 60 receivers, where among the dictators 40 individuals received the large pie and 20 the small pie. As mentioned before, dictators always knew the exact size of the pie, while in the DG-II receivers were only informed about the distribution of the potential pie size.

Participants were provided with instruction sheets and briefed, before filling in a control questionnaire to check their understanding. They were then allowed to proceed after checking their answers and clarifying their understanding if needed. The experiment was conducted with paper and pencil. We provided subjects with partitioned voting cubicles for them to make decisions in privacy and anonymity.

\footnotetext{
${ }^{10}$ Assuming common knowledge of preferences or consistent beliefs in a Bayesian framework, a positive test implies that subjects value social confirmation per se. Expressing gratitude is an example of social confirmation.
} 
To avoid framing effects, e.g. making the 50-50 split salient using round numbers, givers were asked how much of a surplus with a un-rounded number of 19.55 experimental currency units (ECU) for the large pie, or in the case of having to split a small pie 2.25 ECU (only in the DG-II), to give and to keep. This was, after conversion of $€ 1=1.955 \mathrm{ECU}$, equivalent to $€ 10$ and $€ 1.15$ respectively.

Procedures were very similar over the four games. Participants received an envelope containing the written instructions and the amount of the pie, split into many experimental currency coins, to increase the precision at which offers could be made. Givers then left the amount for the receiver in the envelope and stated the received amount (either 19.55 or 2.25 ECUs, only in case of the dictator game with incomplete information) and in all games the transferred amount to the receiver on their decision sheet for our records. Decision sheets marked with pseudonyms chosen by the participants, were placed in envelopes and then collected by the experimental assistants. The envelopes, also marked with pseudonyms, were then deposited into a box where all proposals were collected.

Two neutral experimental assistants in a third room checked if the amount in each envelope was equal to the amount stated by the giver in the decision sheet - they always were. The box was then transferred to the next room and the envelopes were randomly distributed among the receivers in the dictator games and the impunity games.

In the dictator games, receivers simply took the money and left. Receivers in the impunity games were asked to either take the transfer or leave it in the envelope. All envelopes were collected in the impunity games and the pseudonyms of the givers were informed what we found in the envelopes (either nothing if the giver had not sent anything or if the receivers had chosen to take the transfer out of the envelope) or the left coins if the receiver had decided to return the transferred ECUs. (If receivers decided to reject the transfer, they always returned the full amount.) To convert the received ECUs to Euros, and to be paid in strict anonymity, the participants went to a third person who was the cashier of this and of other experiments and who could not deduct from the exchanged ECUs in which experiment the ECUs were earned. Subjects were thus paid in true anonymity, which is important as it removes possible confounds from subjects behaving under the influence of social observation, i.e. to behave under the pressure of being observed (see Bolton and Zwick, 1995). 
Altogether, subjects received a $€ 5$ show-up fee and the share they were allocated in the game. On average they earned $€ 9.18$. In the two dictator treatments, the average earning was $€ 8.70$ (because every third dictator had received the small pie); in the two impunity games the average earnings were slightly below $€ 10$ due to rejected offers. Each session lasted about 30 to 45 minutes.

\section{Results}

Table 1 reports the transfers in $€$ and statistics of all games for decisions made when $\mathrm{S}$ $=19.55 \mathrm{ECU}=€ 10$, the large surplus. Figure 1 shows distributions of offers for each game.

\section{<Insert Table 1 and Figure 1 about here>}

First of all there were positive offers across all games. With the exception of two offers in the DG-II with the small pie nobody offered more than half of the pie. Positive offers were rejected in the impunity game. Behavior in our standard Dictator Game with complete information (DG-CI) is comparable to previous studies with analogous design. The mean offer in DG-CI (20.4\%) is similar to those of earlier experiments. For example, Forsythe et al. (1994) observed a mean offer of $23.3 \%$. Using their experiment as a benchmark, a Mann Whitney U (MWU) test shows that the difference between the two means is insignificant $(\mathrm{z}=-0.480 ; \mathrm{p}=0.631)$. A twosample Kolmogorov Smirnov (K-S) test shows that the two distributions are not significantly different $(z=0.871 ; p=0.433)$. Thus, we can use the behavior in the DG$\mathrm{CI}$ as benchmark for the other three treatments.

Result 1 (money maximization): Offers are positive on average in the dictator and impunity games, and rejections are observed in impunity games. $\mathrm{H} 1$ is rejected.

Comparing behavior of individuals in the Dictator Game with incomplete information (DG-II) with the DG-CI, it is salient that the mean offer in DG-II is $11.4 \%$, almost half that of DG-CI. This difference is significant (MWU: $z=3.056 ; p=0.001$, 1-tail). The distributions are also significantly different (K-S: $z=1.677 ; p=0.002,1$ tail): offers skew to the left in DG-II (skewness test: $p=0.001)$ but not in DG-CI ( $p=$ 
0.106, 2-tails). Models based on payoff-based social preferences do not predict such a difference.

This variation is in line with image concerns, as stated in hypothesis 3 . It suggests that givers hide behind the small surplus because they care about their image from the receiver's perspective and not merely about the payoffs of the receivers. In DG-II, 24 of the 26 offers below $10 \%$ of the large pie are at most half the value of the small pie (13 of 15 if we exclude zero offers). In DG-CI, the shares of zero transfers and of transfers below the value of the small pie were much lower. Overall, $60 \%$ of the subjects offered less than half the value of the small pie in DG-II, while only $22.5 \%$ made such low offers in DG-CI. A Fisher's test confirms that this difference is significant $(p=0.017) .11$

With respect to the small pie in the DG, behavior of those who received the large pie but where hiding behind the small pie was similar to the behavior those who actually received the small pie. Dictators either gave nothing (in 5 out of 20 cases of the DG-II with the small pie and 11 out of 40 cases of the DC-II with the large pie) or (in 14 cases of the small DG-II and 12 cases of the large DG-CI) around half of the small the pie (around 1.1 ECUs which transfers to 0.57 Euros). Given the tiny absolute size of the pie, we refrain from interpreting the higher willingness of dictators in this game for an equal split. ${ }^{12}$

Result 2 (social preferences): Offers are significantly less in dictator games with incomplete information on the surplus size, compared to those in the dictator game with complete information. The majority of givers who received a large pie offered less than half of the small pie. $\mathrm{H} 2$ is rejected.

Differing behavior is also observed in the Impunity Games. The mean offer in IG-CI is $22.2 \%$. Mean offers are not significantly different comparing DG-CI and IGCI (MWU: $\mathrm{z}=-0.57 ; \mathrm{p}=0.478,1$-tail). From Figure 1, one can tell, however, that the distribution of transfers is shaped differently: the distribution for DG-CI resembles a distribution similar to a normal distribution (between the limits of no transfer and the

\footnotetext{
11 Interestingly enough, if one considers only positive offers, because zero offers are not 'hiding' behind the small pie, the mean offer in DG-II is $69.5 \%$ that of DG-CI, uncannily alike the ratio of the value of the pie in DG-CI and that expected in DG-II, $2 / 3(10)+1 / 3(1.15)=7.05$, i.e. $70.5 \%$ the value of the pie in DG-CI.

12 The data for the outcomes in the small pie of the DG-II are available from the authors on request.
} 
transfer of half of the pie), whereas that for IG-CI is (more) ${ }^{13}$ bimodal and resembles a u-shape with a kink on the right side of the distribution. The tendency for offers in IGCI to move away from the mean to the extreme points of 0 and $1 / 2$ is precisely in line with the assumption of image concerns. A Siegel-Tukey test confirms that more extreme values, moving away from the center, tend to be observed in the IG-CI ( $\mathrm{z}=$ $2.14 ; \mathrm{p}<0.05)$. Fisher's tests also show that there are significantly more subjects at the extreme points of $0(10 \%$ in DG-CI versus $26 \%$ in IG-CI; $p=0.046)$ and $1 / 2(12 \%$ in DG-CI versus $28 \%$ in IG-CI; $p=0.064$ ). It should further be emphasized that 6 of the 7 receivers who received $10 \%$ of the pie or less, rejected these offers. All offers above $10 \%$ of the pie were accepted.

Result 3 (image concerns): Offers are distributed bimodally at zero and half the surplus in the impunity game with complete information. Positive offers of $10 \%$ or less are mostly rejected. This is support for H3.

The mean offer in IG-II at $15.7 \%$ is not significantly different from that of DG$\mathrm{CI}$ at 20.4\% (MWU: $\mathrm{z}=1.892 ; \mathrm{p}=0.585,2$-tails). Casual eyeballing of Figure 1, however, indicates that many more offered nothing in the IG-II than in any other treatment. About half of the subjects (44\%) offered 0 in IG-II, in stark contrast to the $10 \%$ of subjects in DG-CI, and the $26 \%$ in IG-CI (Fisher's: $p=0.0003$ and 0.046 , respectively). The IG-II distribution is significantly skewed to the left ( $p=0.030,2-$ tails). Only $10 \%$ offered half the pie in IG-II, while $28 \%$ did so in the IG-CI (Fisher's: $p$ $=0.02$ ); a Moses test of extreme reactions shows that there is a significantly more extreme leftward bias in IG-II than in IG-CI $(\mathrm{p}=0.004)$.

DG-CI and IG-II are also distributed differently (K-S: $z=1.603 ; \mathrm{p}=0.002,1$ tail). However, if we control for the leftward bias of 0 offers in the IG-II, i.e. to restrict the sample to positive offers, then we cannot reject the null that the distributions in DG$\mathrm{CI}$ and DG-II are equal (K-S: $\mathrm{z}=1.571 ; \mathrm{p}=0.377,1$-tail). This result tells us that the main difference between the distributions of DG-CI and IG-II are in the extremity of 0 offers in IG-II, but not overall. It implies that this extreme mode is made up of a certain type of giver that is randomly distributed between 0 and $50 \%$ in the DG-CI. Finally,

\footnotetext{
${ }^{13}$ Linear altruism predicts bimodality at 0 and 1 , but not a variation across treatments. With respect to efficiency-oriented approaches one could argue that if givers anticipate rejections, they may adjust their transfers in the IG-CI and IG-II to avoid waste, but an efficiency-oriented approach would not expect a bimodal behavior of giving.
} 
note that only one offer (of 1\%) was rejected, and almost nobody (2 out of 50 subjects) made "gratuitous" - or "insulting" - offers below $10 \%$.

Result 4 (social confirmation): Offers are distributed unimodally at 0 in the impunity game with incomplete information, and positive offers of $10 \%$ or less are virtually unobserved. This is support for $\mathrm{H} 4$.

\section{Discussion and Conclusion}

In this paper, we analyze driving forces behind gift giving. To do so we use variants of dictator and impunity games. While self-interest and social preferences predict no differences in behavior across the four games, we observe significant differences. The variations across treatments are compatible with image concerns as one important driving force. Subjects with image concerns are motivated to appear fair to others rather than to actually be fair, thus placing value on positive feedback in this respect. On the one hand, they are willing to sacrifice monetary payoffs to avoid negative feedback. On the other hand, they lose the incentive to give in the absence of feedback.

In the dictator game with incomplete information, givers manipulated receiver expectations by transferring half of the value of the small surplus when they actually had a large surplus to split. Doing so increases monetary payoffs and avoids the appearance of unfairness to others. What might appear fair to the uninformed receiver is clearly unfair in the eyes of the giver. Consistently, in the impunity game with complete information, where receivers can reject gifts with no payoff consequence to givers, we observed a bifurcation in behavior. The available option of rejection for the receiver induced a substantial share of givers to either keep the complete endowment to themselves or to increase the amount in a way that they could increase the chances of acceptance. They did so anticipating that receivers were ready to reject small transfers below 10 percent. Thus, some givers were willing to pay a "fairness premium" to ensure that receivers would perceive them as fair, while others chose to abandon the costly pursuit of appearing fair.

Removing feedback on receiver decisions in impunity games has a strong effect. Many offers drop to zero implying that image concerns confer value on social confirmation of having been perceived as fair. Without having this information image- 
concerned givers are no longer willing to pay the "fairness premium" for a positive image. Thus, behavior in the impunity game under incomplete information reveals that removing social confirmation eradicates image-related incentives to give. Overall, the predictions from our hypotheses related to image concerns are compatible with the outcomes in our four games. It explains why givers in the impunity game with complete information moved to the two extremes of the distribution, at zero and around the equal split. Consider the tradeoff between (A) insuring against image loss via acceptance by increasing offers toward the equal split, and (B) settling for image loss from rejection while keeping more of the surplus by reducing offers to zero. It is reasonable to assume a distribution of types where $\mathrm{A}$ is preferred to $\mathrm{B}$ for some and vice versa for others.

In this sense, fundraisers should be aware of the bifurcating effect of the impunity game. If they fine-tune their activities towards the impunity game, paying attention to the image concerns of their donors might become crucial. With this effect in mind they will be able to induce a kind of a screening process among their potential donors with those who do care about their image willing to increase their payments. Whether this pays for the fundraisers depends on whether they will be able to make (A) larger than (B).

Our analysis reinforces the psychological research of Darley and Fazio (1980), who define "expectancy confirmation" in their development of Merton's $(1948,1957)$ psychological concept of self-fulfilling prophecies. Social interactions are described as sequences where a perceiver develops and then acts in accord with the expectations of a target. The target interprets the perceiver's action and acts on this interpretation. Finally, the perceiver interprets the target's action. One's expectation therefore biases another's behavior in ways that we can interpret as confirming the expectation. In the context of gift giving, the giver ("perceiver") develops expectations of the receiver ("target"), and chooses how much to give. The receiver then interprets the giver's gift ("perceiver's action") and acts on this interpretation. The giver infers ("perceives") his portrayed image from the receiver's response ("target's action). In dictator games, a receiver cannot act on this interpretation because she cannot respond. Our impunity games allow for feedback and therefore extend Darley and Fazio's sequence.

Our experimental outcomes also contribute to the ongoing debate regarding the relative strengths of equity and efficiency concerns in the literature on social preferences with several experiments showing that there is a "trade-off between efficiency and equity motives" (Bolton and Ockenfels, 2006, 1906). This tradeoff is not 
ostensibly apparent in the impunity games. On the one hand, receivers are willing to reject low offers in impunity games, thereby decreasing equity and efficiency. On the other hand, some givers preempt this by increasing offers to avoid rejection and in turn decreasing inequity, while others decrease offers to zero and in turn increase inequity instead. Both strategies on the givers side improve, however, (expected) efficiency.

These behaviors are puzzling when put together. First, receivers who reject offers are giving up monetary payoffs, equity and efficiency, rather than trading them off each other as the social preferences literature had noted. Second, in the same game some givers give up monetary payoffs for equity and efficiency, while other givers do the opposite. Thus, the concerns revealed by the various strategies across roles seem contradictory and inconsistent. The key to this puzzle is found by identifying a further component of motivation against which monetary payoffs, equity, and efficiency can be traded off: image concerns.

Thus, the main contribution of this paper is that subjects trade off money, equity, efficiency, and image concerns with social confirmation playing a significant role in the transmission of image concerns to behavior. 


\section{References}

Andreoni, J. and B.D. Bernheim (2009): Social Image and the 50-50 Norm: A Theoretical and Experimental Analysis of Audience Effects. Econometrica 77, 16071636.

Andreoni, J. and J.H. Miller (2002): Giving According to GARP. An Experimental Test of the Consistency of Preferences for Altruism. Econometrica 70, 737-753.

Andreoni, J. and J.M. Rao (2011): The Power of Asking. Journal of Public Economics 95, 513-520.

Ariely, D., Bracha, A. and S. Meier (2009). Doing Good or Doing Well? Image Motivation and Monetary Incentives in Behaving Prosocially. American Economic Review 99, 544-555.

Battigalli, P. and M. Dufwenberg (2009): Dynamic Psychological Games. Journal of Economic Theory 144, 1-35.

Bicchieri, C. and A. Chavez (2010): Behaving as Expected: Public Information and Fairness Norms. Journal of Behavioral Decision Making, 23, 161-178.

Bolton, G.E.; Katok, E.; Zwick, R. (1998): Dictator Game Giving: Rules of Fairness versus Acts of Kindness. International Journal of Game Theory 27, 269-299.

Bolton, G.E.; Ockenfels, A. (2000): A Theory of Equity, Reciprocity and Competition. American Economic Review 90, 166-193.

Bolton, G.E. and Ockenfels, A. (2006). Inequality aversion, efficiency, and maximin preferences in simple distribution experiments: comment. American Economic Review, 96(5):1906-1911.

Bolton, G.E. and Zwick, R. (1995): Anonymity versus Punishment in Ultimatum Bargaining. Games and Economic Behavior 10, 95-121.

Breitmoser, Y., and Tan, J.H.W. (2013): Reference Dependent Altruism in Demand Bargaining. Journal of Economic Behavior and Organization 92, 127-140.

Charness, G. and Rabin, M. (2002): Understanding Social Preferences with Simple Tests. Quarterly Journal of Economics 117, 817-868.

Croson, Rachel T. A., (1996): Information in Ultimatum Games: An Experimental Study. Journal of Economic Behavior and Organization 30, 197-212.

Dana, J., Cain, D. M., Dawes, R. M. (2006): What You Don't Know Won't Hurt Me: Costly (but Quiet) Exit in Dictator Games. Organizational Behavior and Human Decision Processes 100, 193, 201.

Dana, J., Weber, R. A., Kuang, J. X. (2007): Exploiting Moral Wiggle Room: Experiments Demonstrating an Illusory Preference for Fairness. Economic Theory 33, 67-80.

Darley, J. M., and Fazio, R. H. (1980): Expectancy Confirmation Processes Arising in the Social Interaction Sequence. American Psychologist 35(10), 867-881. 
DellaVigna, S., List, J.A. and U. Malmendier (2012): Testing for Altruism and Social Pressure in Charitable Giving. Quarterly Journal of Economics 127, 1-56.

Dufwenberg, M. and Kirchsteiger, G. (2004): A Theory of Sequential Reciprocity. Games and Economic Behavior 47, 268-298.

Eckel, C.C. and P.J. Grossman (1996): Altruism in Anonymous Dictator Games. Games and Economic Behavior 16, 181-191.

Engel, Christoph (2011): Dictator Games: a Meta Study. Max Planck Institute for Research on Collective Goods, Bonn 2010/07.

Engelmann, D.; and Strobel, M (2004): Inequality Aversion, Efficiency, and Maximin Preferences in Simple Distribution Experiments. American Economic Review 94 4, 857-69.

Falk, A.; Fischbacher, U. (2006): A Theory of Reciprocity. Games and Economic Behavior 54, 293-315.

Fehr, E., Schmidt, K. (1999): A Theory of Fairness, Competition and Cooperation. Quarterly Journal of Economics 114, 817-868.

Forsythe, R.; Horowith, J.L.; Savin, N.E.; Sefton, M. (1994): Fairness in Simple Bargaining Experiments. Games and Economic Behavior 6, 347-369.

Franzen, A. and S. Pointner (2012): Anonymity in the Dictator Game Revisited. Journal of Economic Behavior and Organization 81, 74-81.

Greiner, B. (2004): Bounded Rationality in Bargaining Games: Do Proposers Believe That Responders Reject an Equal Split? Dis. Paper No. 11, Univ. of Cologne.

Güth, W.; Huck, S.; Ockenfels, P. (1996): Two-level Ultimatum Bargaining with Incomplete Information: An Experimental Study. Economic Journal 106, 593604.

Kritikos, A.S.; Bolle F. (2001): Distributional Concerns: Equity or Efficiency Oriented? Economics Letters 73, 333-338.

Krupka, E. L., and Weber, R. A. (2013): Identifying Social Norms Using Coordination Games: Why does Dictator Game Sharing Vary? Journal of the European Economic Association 11(3), 495-524.

Merton, R. K. (1948): The Self-fulfilling Prophecy. Antioch Review 8, $193-210$.

Merton, R. K. (1957): Social Theory and Social Structure. New York: Free Press of Glencoe.

Ockenfels, A., Werner, P. (2012): Hiding behind a small Cake in a Newspaper Dictator Game. Journal of Economic Behavior and Organization 82, 82-85.

Straub, P.G., Murnighan. J.K. (1995): An experimental investigation of ultimatums: Common knowledge, fairness, expectations, and lowest acceptable offers. Journal of Economic Behavior and Organization. 27, 345-364. 
Table 1 Data on offers and descriptive statistics for all games*

\begin{tabular}{|c|c|c|c|c|}
\hline Transfer in $€$ & DG-Cl & DG-II large & $\mathrm{IG}-\mathrm{Cl}$ & IG-II \\
\hline 0 & 4 & 11 & 13 & 21 \\
\hline 0.1 & 0 & 3 & 0 & 1ro \\
\hline 0.16 & 1 & 0 & 0 & 0 \\
\hline 0.26 & 0 & 2 & 0 & 0 \\
\hline 0.31 & 1 & 0 & 0 & 0 \\
\hline 0.42 & 0 & 1 & 1ro & 0 \\
\hline 0.52 & 1 & 2 & 1ro & 0 \\
\hline 0.57 & 2 & 5 & 0 & 0 \\
\hline 0.62 & 2 & 1 & 3ro & 1 \\
\hline 0.94 & 0 & 1 & 0 & 0 \\
\hline 1 & 1 & 0 & 1ro & 0 \\
\hline 1.04 & 0 & 1 & 2 & 4 \\
\hline 1.15 & 6 & 4 & 0 & 1 \\
\hline 1.67 & 3 & 0 & 0 & 3 \\
\hline 2 & 0 & 0 & 3 & 0 \\
\hline 2.08 & 1 & 0 & 1 & 0 \\
\hline 2.19 & 6 & 0 & 6 & 6 \\
\hline 2.54 & 0 & 1 & 0 & 0 \\
\hline 2.59 & 1 & 0 & 1 & 0 \\
\hline 2.66 & 0 & 2 & 0 & 0 \\
\hline 2.92 & 0 & 1 & 0 & 0 \\
\hline 3 & 0 & 0 & 2 & 2 \\
\hline 3.23 & 2 & 0 & 1 & 0 \\
\hline 3.65 & 1 & 0 & 1 & 0 \\
\hline 3.75 & 0 & 1 & 0 & 3 \\
\hline 4 & 1 & 0 & 0 & 2 \\
\hline 4.27 & 1 & 0 & 0 & 1 \\
\hline 4.48 & 0 & 1 & 0 & 0 \\
\hline 4.5 & 1 & 0 & 0 & 0 \\
\hline 4.69 & 0 & 0 & 1 & 0 \\
\hline 4.74 & 0 & 1 & 0 & 0 \\
\hline 4.8 & 2 & 2 & 6 & 1 \\
\hline 5 & 3 & 0 & 7 & 4 \\
\hline Mean in \% & 20.4 & 11.4 & 22.2 & 15.7 \\
\hline Variance & 2.624 & 2.302 & 3.814 & 3.131 \\
\hline Skewness & 0.6 & 1.481 & 0.292 & 0.752 \\
\hline Kurtosis & -0.847 & 0.959 & -1.469 & -0.849 \\
\hline
\end{tabular}

* In the Impunity Games an "ro" denotes "rejected offers" by receivers. The data reported for the DG-II covers only subjects who received the large surplus. The data for the small surplus of the DGII are available on request. 
Figure 1 Distribution of offers for all games*

DG-Cl

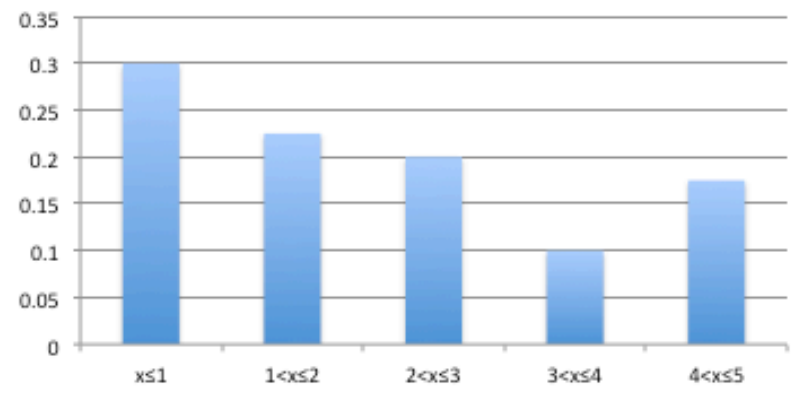

IG-CI

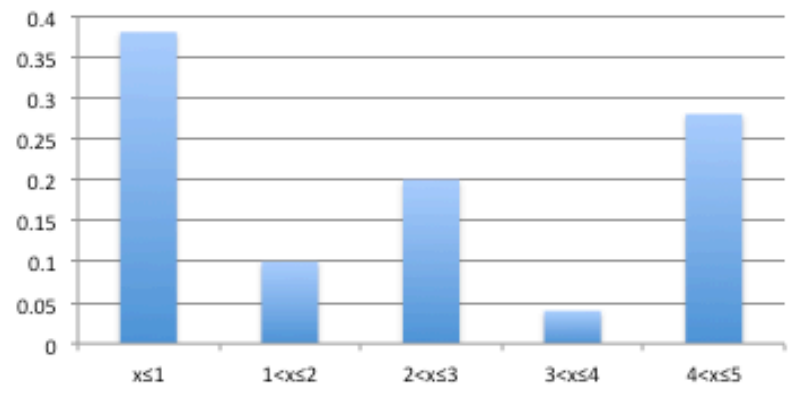

DG-II

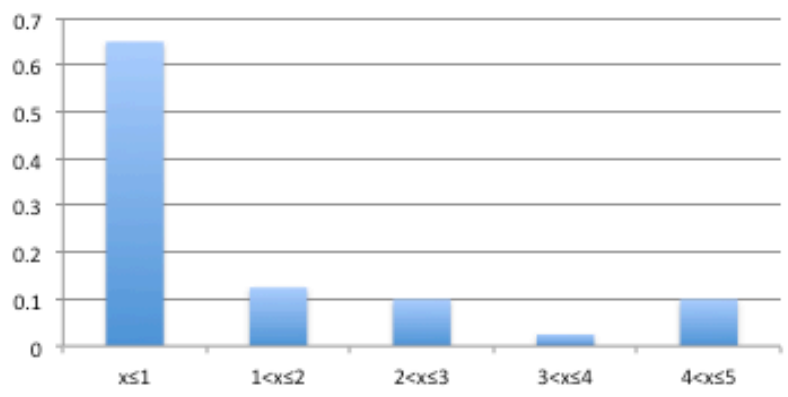

IG-II

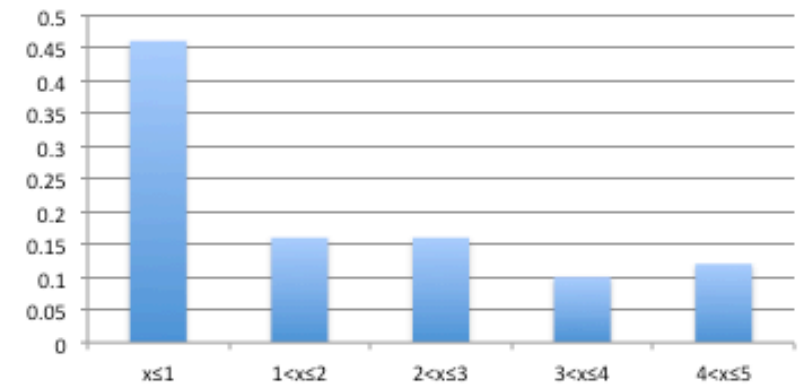

* Offers are given on the $\mathrm{x}$-axis, and frequencies on the $\mathrm{y}$-axis. Top row: dictator games (DG); bottom row: impunity games (IG); left column: complete information (CI); right column: incomplete information (II). 


\section{Appendix A: Instructions to player A in the four experiments}

In the description the instructions for player A are presented. Differences corresponding to the four treatments are indicated in boldface. The instructions for Person B are available on request.

\section{Instructions For Player A}

You have been asked to participate in an experiment on individual decision making. You will receive $5 €$ for your participation in addition to further money which you may earn based on decisions made in the experiment and which will be paid to you in a different room after the session has ended. Before you make any decision please read carefully the following instructions. If you have any questions, don't hesitate to ask the experimenter.

In this experiment each of you will be paired with a different person who is in another room. This is room A and you are Person A. The person who will be paired with you is Person B in Room B. You will not be told who these people in Room B are, neither during nor after the experiment, and they will not be told who you are, neither during nor after the experiment. You will notice that there are other people in the same room with you who are also participating in the experiment. You will not be paired with any of these people. The decisions that they make will have no effect on you nor will any of your decisions affect them.

The experiment is conducted as follows: A sum of 19.55 Experimental Currency Units (ECU) (ECU 2.25) has been allocated to you in coins in the envelope. The transfer rate of ECU to Euro is 1.955 .

Game 1, Game 3, Game 4: The person B who is anonymously matched with you knows that you have received this amount. You are now asked to propose how much of this sum Person $\mathrm{B}$ and you should receive. You are free to propose any amount to person B: nothing, something or the whole sum.

Game 3 (in addition): Person B in room B may accept or reject your proposal. If person B accepts your proposal, both of you will receive the respective amount. If person $\mathrm{B}$ rejects your proposal, you will keep your own share of the pie and person B will receive no payoff. At the end of the session you will be informed about the decision of B, by using your pseudonym. B is also informed that you know that B will give feedback on your decision. Communication is done via pseudonyms.

Game 4 (in addition): Person B in room B may accept or reject your proposal. If person B accepts your proposal, both of you will pocket the respective amount. If person B rejects your proposal, you will keep your own share of the pie and person B will receive no payoff. You will not be informed about the decision of $\mathrm{B}$ and $\mathrm{B}$ knows that you will not be informed about B's decision.

Game 2: There are 39 (40) more players who have received ECU 19.55 and 20 (19) more players who received ECU 2.25. Person B who is paired with you does not know the exact amount allocated to you. Person B knows that you have received ECU 2.25 with a probability of $33.3 \%$ and ECU 19.55 with a prob. of $66.7 \%$. You are asked to propose how much of the amount of ECU 19.55 (ECU 2.25) each person is to receive. You are free to propose any amount you like to person B: nothing, something or the complete sum. 
For your decision you may use the cubicles in the room. If you made your decision about the amount which you like to propose to person B, put the respective amount into the envelope and put the envelope into the box next to your cubicle.

Indicate a pseudonym for yourself on the second note and put the note into the envelope, as well.

Then you may pocket your ECU which you have allocated to yourself. Do not talk to the other people in your room until your session is completed. Do not be concerned if other people make their decision before you. After the session please go to room XXX to change your ECU into Euro. 